\title{
AOR
}

Selected Papers of \#AolR2021:

The 22nd Annual Conference of the

Association of Internet Researchers

Virtual Event / 13-16 Oct 2021

\section{THE IN(TER)DEPENDENCIES OF MOBILE ONLINE AND OFFLINE SPACES: REFLECTIONS ON METHODS, PRACTICES, ETHICS}

Katja Kaufmann

University of Innsbruck / CMC Vienna

Monika Palmberger

University of Vienna / University of Leuven

\section{Introduction to the Panel}

Mobile media technologies place users in digital (online) as well as physical (offline) spaces in novel ways, opening up new environments of affordances. In everyday life these mobile online and offline spaces are increasingly interdependent and interwoven in manifold ways. Practices, experiences, meanings, and expectations are negotiated across these spaces, while at the same time they are bound by the respective logics and limitations, leading to new interrelations and contradictions. The mobile, interlocking but non-converging nature of these online and offline spaces involves issues of access and power in struggles over in(ter)dependencies and leads to significant method(odolog)ical, practical and ethical challenges for researchers, to which the current COVID-19 pandemic only adds complexity.

Meanwhile, in the discussion of research findings as well as in methodological literature, the specific challenges associated with researching the intersections of online and offline spaces, especially under mobile conditions, are rarely explicitly addressed. For this reason, this panel seeks to advance methodological scholarship and crossdisciplinary exchange on prevalent and emerging ICTs and their embeddedness in everyday practices across mobile online and offline spaces.

Paper 1, Smartphones in Precarious Contexts: Ethnographic Reflections on the Use of Mobile Technologies in Favelas in Rio de Janeiro (Brazil), investigates the everyday use of smartphones in the impoverished and unequal contexts of Brazilian favelas. Based on ethnographic data from both in-person and digital conversations, interactions and observations, the author discusses the methodological contributions that ethnography presents as a tool for dealing with transitions between online and

Suggested Citation (APA): Kaufmann, K.; Palmberger, M., Parreiras, C., Bussoletti, A., Belotti, F., Comunello, F., Donato, S., Wagenaar, W., Bermúdez, J., Schweiger, M., \& Wimmer, J. (2021, October). The in(ter)dependencies of mobile online and offline spaces: Reflections on methods, practices, ethics. Panel presented at AoIR 2021: The 22nd Annual Conference of the Association of Internet Researchers. Virtual Event: AolR. Retrieved from http://spir.aoir.org. 
offline environments, and for considering the particularities of the incorporation of technologies in everyday life in contexts of social and digital inequality. The paper thus seeks to contribute to an understanding of smartphones as mediators between digital/online and physical/offline relationships.

Paper 2, In the Backstage of Fridays for Future between (Mobile) Online and Offline Practices, is based on multimodal ethnography and examines how Fridays for Future (FFF) activists are seamlessly organized between online and offline environments. Conceptualizing Mobile Instant Messaging services (MIMs) as the 'backstage' of activism, the authors argue that we need to consider physical and digitally-mediated environments as a whole to understand FFF's organizational dynamics, identity-building processes, and sense-making related to social media usages. The authors advocate the use of methods that value the mutual influence of culture and technology, such as their qualitative multimodal research design that combines participant observation and digital ethnography across multiple settings (WhatsApp, Zoom, physical locations).

Paper 3, Studying the Everyday Lives of Media Fans: Practical and Ethical Challenges, gives insight into the significant challenges of studying how online fan practices and experiences are embedded in and interact with the everyday offline contexts from which individual fans engage in them. Using non-media-centric, ethnographic research on the day-to-day lives of media fans, the author reflects on addressing the geographical delimitations of doing face-to-face fieldwork as well as on having to adapt established ethnographic methods to online approaches during ongoing research in light of the COVID-19 pandemic and considers some of the practical and ethical challenges that come into play when studying how pseudonymous identities and sensitive online practices are embedded in people's everyday lives.

\section{Paper 4, Ethnographing Between Spaces: Researching TikTok from an}

$E^{3}$ thnomusicological Perspective, deals with the challenge of ethnomusicology to research musicality in its holistic course of performance. Using the case of the videosharing app TikTok, the paper discusses the analysis of multimedia musical practices as a necessary shift in thinking about the importance of internet in the everyday life of the actors, their musical practices, as well as the recognition of internet as an embodied experience beyond the real/virtual dichotomy. The author argues that in order to capture the deterritoralization and multimedia reality of musical practices, researchers need a threefold focus on interactions, interrelations and enabling processes. Moreover, the author opens a discussion on the ethnographic field and its conceptualization in the context of deterritorialization and the multimedia reality of the musical practices studied.

Paper 5, Methodological Reflections on Capturing Augmented Space: Insights from an Augmented Reality (AR) Field Study, provides insights into the methodological challenges and opportunities of researching the emergent phenomenon of Augmented Reality and its impact on people's perception of urban space in daily life. The authors share their experiences in applying a range of qualitative and quantitative approaches which proved valuable for capturing the reception of space, including thinking-aloud-protocols (TAP) to analyze the influence of AR on spatial perception and meaning, a standardized online survey to capture spatial meaning, and the collection of 
spatial movement using locative tracking via the head-worn AR glasses. The COVID-19 pandemic posed additional challenges to the practical use of the technical instruments.

With these five papers, the panel presents a thought-provoking range of examples of research into phenomena at the intersections of mobile online and offline spaces and the associated experiences as well as methodological challenges of researchers in dealing with issues of in(ter)dependence at all levels. 


\section{SMARTPHONES IN PRECARIOUS CONTEXTS: ETHNOGRAPHIC REFLECTIONS ON THE USE OF MOBILE TECHNOLOGIES IN FAVELAS IN RIO DE JANEIRO (BRAZIL)}

Carolina Parreiras

State University of Campinas (Unicamp)

\section{Introduction}

The aim of this paper is to reflect on the theoretical, ethical and methodological challenges involved in conducting research that focuses on the use of smartphones, as well as research that is carried out through the use of mobile devices. I take Daniel Miller's (2021) recent proposals regarding research with smartphones as a starting point and inspiration. Miller seeks to think of these devices not only as material devices in themselves, but as places we inhabit and in which we live. The data on which this paper is based is derived from an ethnographic research carried out among favela dwellers in the city of Rio de Janeiro (Brazil).

It is important to note that, in these favelas, smartphones have become an essential means for accessing social services, school, and work, as well as for sociability and accessing information. As Christine Hine (2015) proposes, there is a need for greater attention to the "embedded, embodied and everyday" internet. I am especially interested to discuss the everyday character of the use of smartphones in impoverished contexts, how smartphones work as the technological device through which it is possible to map the transits between online and offline spaces, as well as the many inequalities that these uses point to.

\section{Context}

Favelas are impoverished places marked by what we could call structural and material precariousness, in which residents face difficulties in accessing basic services, housing, water, and basic sanitation, for example. As they are also places marked by different forms of urban violence, with increasing clashes between police/army and groups linked to drug trafficking, I use the fictitious name Complexo to name the favelas addressed in this paper.

The context of the Complexo reflects the general data around access to the Internet and to technological devices in Brazil. According to one of the surveys available on use of technology in Brazil (the ICT Households), Brazil is still quite unequal in terms of access, with $58 \%$ of internet users in the country using their smartphone as the only means of access.

\section{Methods}

The COVID-19 pandemic impacted the ways in which the research was carried out, as it made any type of in-person/offline fieldwork incursion impossible. My contacts with my interlocutors started to be exclusively through digital means, specifically with the use of 
WhatsApp. WhatsApp is a strategic application because it is used by most of my interlocutors functioning, as suggested by Cruz and Harindranath (2020), as a "technology of life" that shapes the everyday life and serves for a big range of activities. Another important point is that WhatsApp allows for different forms of exchange: synchronous and asynchronous, by text, video or audio messages. These aspects are useful because they point to the different significances each format receives in the daily uses and tells us about the digital literacies associated with social inequalities (for example, why audio messages are preferred in detriment to text messages).

I aim to advance our understanding of smartphones as mediators of digital/online and analogic/offline relationships, creating hybrid and everyday spaces of life. Ethnography offers methodological contributions as a tool for dealing with these hybrid spaces, and for considering the particularities of the incorporation of technologies in everyday life. As I am interested in the microscopic sphere of life, summarized in this idea of everyday, ethnography can account for the quotidian uses of smartphones. The bet on everyday character of life is not new to Internet Studies. I use it, following Das (2020), as a way that helps us to understand the ordinary acts of life. I focus my reflections on conversations and interactions with women living in these favelas, carried out in person (before the COVID-19 pandemic) and from WhatsApp (before and during the pandemic). In what concerns ethics, all participants gave formal consent - by text or audio message, during the pandemic, and by signing a Term of Consent before the pandemic.

\section{Discussion}

The ethnographic data shows that this tool is the predominant (and almost exclusive) means of accessing the Internet in these favelas. The digital inequality manifests itself both in terms of access to technology and in terms of digital literacy, and it is common for a single device to be shared amongst the members of a single household. Thus, smartphones are the main device for accessing the Internet because they are more affordable and because they allow for the use of mobile connection networks, also at a lower cost. A large part of the residents with whom I had contact use plans called "prepaid" - that is, a fee is paid for credits that serve for using the connection during a certain amount of time. Such plans guarantee cheaper access to the Internet and, in most cases, the data plans do not charge for using WhatsApp app on your phone. Regarding digital literacy, most users navigate popular applications (WhatsApp, Facebook, Instagram) relatively easily, but they have a lot of difficulty with other sites or applications such as e-mail and banks (essential for receiving federal government benefits, for example). Something very common is the loss of passwords, and there is a lack of knowledge of the possibility of recovering them, which causes users to create innumerous new accounts on social networks, e-mails and websites.

Thus, I provide an analysis that takes into account both the contexts of use of smartphones, and their particular materiality as technological devices that are considered to be high-quality goods with symbolic value in these places. During the period in which it was still possible to go to Complexo to conduct research, I was struck by how smartphones were present in the houses, the narratives about the operations involved in their acquisition (payments in various installments or the purchase of used or 
smuggled devices) and the moments of despair when the devices had problems or simply stopped working. Another common practice is the contracting of local internet services, with broadband connection and of better quality by some residents. When they do this, they become "internet providers" for the neighborhood, renting the use of their connection for a weekly payment. Still, most connections are made exclusively by smartphone.

The pandemic makes inequality even clearer, as smartphones and the internet become essential for carrying out basic daily activities. In many cases, the lack of connection, of the technological device itself, or both, meant that several children were unable to access remote classes or that so many others did not have access to the emergency aid paid by the federal government, which required registration online through an application. The pandemic sheds light on inequality processes that involve access, use and "existential opportunities" (Van Dijk, 2005) offered by the internet, with an increase in digital exclusion processes.

\section{References}

Cruz, E. \& Harindranath, R. (2020). WhatsApp as 'technology of life': reframing research agendas. In: First Monday, 25 (12). https://doi.org/10.5210/fm.v25i12.10405

Das, V. (2020). Textures of the Ordinary. Doing Anthropology after Wittgenstein. New York: Fordham University Press.

Hine, C. (2015). Ethnography for the Internet: embedded, embodied and everyday. Bloomsbury: London.

Miller, D. (2021). A theory of a theory of the smartphone. In: International Journal of Cultural Studies: https://journals.sagepub.com/doi/10.1177/1367877921994574

Van Dijk, J. (2006). Digital divide research, achievements and shortcomings. Poetics, vol. 34, n. 4-5, p. 221-235. 


\section{IN THE BACKSTAGE OF FRIDAYS FOR FUTURE BETWEEN (MOBILE) ONLINE AND OFFLINE PRACTICES}

Arianna Bussoletti

Sapienza University of Rome

Francesca Belotti

Sapienza University of Rome

Francesca Comunello

Sapienza University of Rome

Stellamarina Donato

LUMSA University

\section{Introduction}

Climate activism increasingly gained traction worldwide, with the FridaysForFuture movement (FFF) at its forefront. Social media are pivotal in FFF activities, specifically in recruiting activists, organizing protests, sharing climate-related information and emotions, and building the movement's identity. We discuss how, thanks to multimodal ethnography, we entered FFF-Rome's backstage and understood FFF's organizational dynamics, identity-building processes, and sense-making related to social media usages.

While research has mostly focused on social media as digital activism's 'frontstage', we value Mobile Instant Messaging services (MIMs) as its 'backstage' (Trerè, 2019). Still incipient, literature on MIMs has highlighted the connection between political participation and these platforms' usages (Valenzuela et al., 2019; Milan \& Barbosa, 2020), which provide activists with more private and controlled environments compared to Social Network Sites (SNSs) (Valeriani \& Vaccari, 2018; Gil de Zúñiga et al., 2021). However, MIMs are inscribed in a complex social media ecology (Barnes, 2008; Treré, 2019), with media practices supporting broader grassroots politics (Mattoni, 2020). This poses a methodological challenge to researchers, who must consider how political action unfolds seamlessly between (mobile) online and offline realms, within a mutual shaping relationship between technology and activism (Dennis, 2018).

Within a broader qualitative research, we carried out a multimodal ethnography with(in) the FFF-Rome group (July 2020-January 2021) by blending participant observation and digital ethnography across multiple settings (WhatsApp, Zoom, physical locations, depending on COVID-19 restrictions), thus observing activists' everyday practices in their natural settings (Emerson et al., 2007; Pink, 2016). Multimodal ethnography (Dicks et al., 2006) precisely values the diversity and complementarity of meanings as they emerge from different observation/interaction settings (i.e., 'multi-semiotic modes'), allowing the researchers to present them through a multimedia data recording. In our case, we merged traditional fieldnotes during in-person and on-Zoom assemblies with the novel method of mobile screen capture of significant exchanges on FFF-Rome's WhatsApp group. The group worked as a supportive environment for organizational and 
identity-building processes among users, while screenshots provided complementary, moment-by-moment fine-grained data about users' digital experiences and WhatsApp's social functions (Chiatti et al., 2018; Jaynes, 2019). All data was coded combining deduction and induction towards thematic analysis (Guest et al., 2011).

Two researchers (a 25- and a 35-year-old) were involved in all of FFF-Rome's activities as insiders, while the other two monitored their work, acting as cognitive counterweight to their interpretations. In this, we adopted a transformative paradigm aimed at understanding and practising research as committed to social change and accountable to both the movement and the academy (Mertens, 2007). We fostered genuine bonds with FFF-activists and discussed our research to encourage its appropriation. Consent was gathered iteratively throughout the fieldwork, collectively and explicitly, thus overcoming the mere 'willingness to engage' in favor of a 'wanting to take part' (Nairn et al., 2020). For minors, we collected written consent through a form signed both by them (in recognition of their political agency (Fargas-Malet et al., 2010) and their parents/guardians.

\section{Findings and Discussion}

These methods allowed us to better understand how FFF-activists seamlessly inhabit online and offline environments. Raising a hand to take the floor during physical assemblies translates into sending asterisks in the Zoom chat, while sharing ongoing protests' images on WhatsApp allows at-home activists to participate along with those in the streets. While this confirms digital activism as a fully-embedded political experience, it also shows that this experience is concretely defined at the juncture between social media platforms and physical places.

By being both offline and online, we also saw how FFF-activists assign specific functions and rules to each environment. All topics are/must be discussed in the appropriate forum and way. MIMs groups are dedicated to coordinating strikes and producing SNSs posts, with FFF's official WhatsApp group serving as a think tank. Assemblies establish FFF's political agenda, including identity issues. When the latter arise on WhatsApp they are redirected to the assembly, otherwise, as stated by a user, "it's easy to misinterpret things." When negotiating 'proper' platform usage (i.e. asking a member not to share catholic messages to keep FFF non-religious), FFF-activists relate to the movement's values, which permeate all its backstage environments.

Inclusiveness and horizontality imbue all settings we experienced and, whenever WhatsApp discussions escalate, activists remind each other how to, as stated by another user, properly and peacefully "live [in] this space."

All this provides a 'map' of the overlaps among, and distinctiveness of, different semiotic modes, and also defines the boundaries and consistency of the field as both we and FFF-activists constituted it. These boundaries are continuously negotiated, along with normative manners regulating interaction among activists, coming to define what FFF is, where it stands, and how it behaves, thus configuring FFF-Rome's social media ecology across MIMs groups and SNSs. 


\section{References}

Barnes, S.B. (2008). "Understanding social media from the media ecological perspective.” In E.A. Konijn, Utz S., Tanis M., Barnes S.B.(Eds.), Mediated Interpersonal Communication (pp.14-33). New York: Routledge.

Chiatti, A., Yang, X., Brinberg, M., Cho, M.J., Gagneja, A., Ram, N., Reeves, B., Giles, C.L. (2018). Text extraction from smartphone screenshots to archive in situ media behavior. Proceedings of the Ninth International Conference on Knowledge Capture. Austin: ACM.

Dennis J. (2018). Beyond Slacktivism: Political Participation on Social Media. Cham: Palgrave.

Dicks, B., Bambo, S., Coffey, A. (2006). Multimodal Ethnography. Qualitative Research 6(1):77-96.

Emerson, R.M., Seale, C., Gobo, G., Gubrium, J.F., Silverman, D. (2007). "Working with 'key incidents'." In S. Clive, Silverman, D., Gubrium, J.F., Gobo, G. (Eds.), Qualitative research practice: Concise paperback edition (pp. 427-442). London: Sage.

Fargas-Malet, M., Montserrat, D., McSherry, L.E., Robinson, C. (2010). Research with children: methodological issues and innovative techniques. Journal of Early Childhood Research, 8(2):191-203.

Gil de Zúñiga, H., Ardèvol-Abreu, A., Casero-Ripollés, A. (2021). WhatsApp political discussion, conventional participation and activism: exploring direct, indirect and generational effects. Information, Communication \& Society, 24(2):201-218.

Guest, G., MacQueen, K., Namey, E. (2011). Applied Thematic Analysis. London:Sage.

Jaynes, V. (2019). The social life of screenshots: the power of visibility in teen friendship groups. New Media \& Society, 22(8):1378-1393.

Mattoni, A. (2020). Practicing Media-Mediating Practice| A Media-in-Practices Approach to Investigate the Nexus Between Digital Media and Activists' Daily Political Engagement. International Journal of Communication, 14:2828-2845.

Mertens, D. M. (2007). Transformative paradigm: Mixed methods and social justice. Journal of Mixed Methods Research, 1(3):212-225.

Milan, S., Barbosa, S. (2020). Enter the WhatsApper: Reinventing digital activism at the time of chat apps. First Monday. DOI:10.5210/fm.v25i12.10414 
Nairn, K., Showden, C.R., Sligo, J., Matthews, K.R., Kidman, J. (2020). 'Consent requires a relationship: rethinking group consent and its timing in ethnographic research', International Journal of Social Research Methodology, 23(6):719-731.

Pink, S., Horst, H., Postill, J., Hjorth, L., Lewis, T., Tacchi, J. (2016). Digital Ethnography. Principles and Practice. London:Sage.

Treré, E. (2019). Hybrid media activism: Ecologies, imaginaries, algorithms. London:Routledge.

Valenzuela, S., Bachmann, I., Bargsted, M. (2019). The personal is the political? What do Whatsapp users share and how it matters for news knowledge, polarization and participation in Chile. Digital journalism, 1-21. DOI:10.1080/21670811.2019.1693904

Valeriani, A., Vaccari, C. (2018). Political talk on mobile instant messaging services: A comparative analysis of Germany, Italy, and the UK. Information, Communication \& Society, 21(11):1715-1731. 


\section{STUDYING THE EVERYDAY LIVES OF MEDIA FANS: PRACTICAL AND ETHICAL CHALLENGES}

Welmoed Wagenaar

University of Groningen

\section{Fandom and everyday life}

Digital media and mobile devices have made it possible to engage in new ways with the fictional worlds of Sherlock Holmes, Harry Potter, and many others. Media fans in particular can spend hours exploring and expanding their favorite story worlds and characters via online platforms like Tumblr, Twitter and Discord. What is more, fans can now take their fandoms everywhere in their pockets, these story worlds always being only a few clicks or finger taps away. Existing research on fandom often focuses primarily on online fan practices and how these are embedded in particular online cultures and/or a broader context of social networking, transmedia and participatory culture (cf. Hills, 2017). This overlooks important dimensions of how fictional worlds and fandom are given a place and meaning in people's actual day-to-day lives. At the same time, studying the everyday dimensions of fans' online practices and the complex, often messy intersections between online and offline spaces comes with significant challenges.

\section{Challenges in pandemic times}

In this paper, I discuss some of the practical and ethical challenges I encountered during ongoing non-media-centric, ethnographic research into the everyday lives of media fans. Non-media-centric research focuses on media-oriented practice and discourse, asking what people are doing in relation to media across a range of situations and contexts (e.g. Couldry, 2010; Moores, 2012; Bareither, 2019). Rather than focusing on (an element of) fan culture as it has developed in a particular online space, then, this research specifically examines how fan practices and experiences are embedded in and interact with the everyday contexts from which individual fans engage in them. Over the course of the study, I went from grappling with the geographical delimitations of doing face-to-face fieldwork while starting from online environments that transcend such boundaries, to having to adapt methods like participant observation, video re-enactments (Pink et al., 2016) and the media go-along (Jørgensen, 2016) to online-only formats due to the COVID-19 pandemic. How does one study the intersections between online and offline domains when one cannot move beyond online interactions? Moreover, what ethical dilemmas and practical obstacles may arise in studying dimensions of the everyday when starting from online spaces where people carefully manage the boundaries between different identities and spheres of life?

\section{Adapting methods}

The video re-enactment is a method of observation and audiovisual recording in which research participants re-enact their everyday engagement with media and reflect upon habitual activities and routines by responding to questions or providing ongoing 
commentary of their activity (Pink et al., 2016; Richardson \& Hjorth, 2017). The media go-along is a mobile method where researcher and participant sit down together to simultaneously access a given setting, and participants give visual and verbal tours of a platform (Jørgensen, 2016). Both methods enable researchers to observe and analyze the embeddedness of media in people's everyday life and the use of media 'as it happens'. This includes paying attention to body habits, gestures and other (micro)movements. The methods also rely upon the physical presence of the researcher to give initial instructions, ask questions, and record.

Due to travel restrictions, physical visits became impossible. Instead, I used screensharing technology during video call interviews and asked people to show me their smartphone screen through the webcam to create a virtual media go-along. That way, participants could walk me through their use of different platforms and accounts, revealing details that would otherwise have remained obscured to me as researcher. For example, the go-along showed habitual movements and considerations people made with regard to checking notifications and personal messages, creating and sharing content, and adapting and organizing the platforms in ways that allowed them to prioritize specific interactions over others. In order to gain insight into how this is embedded in participants' day-to-day lives, this research will make use of a semistructured, solicited diary study where participants will be asked to track their fan activities and the physical surroundings and social settings in which those take place for two weeks. By encouraging the use of (audio)visual material in these diaries and discussing them afterwards during an interview, this method forms a helpful strategy to acquire detailed information on moments when the researcher is absent and enables participants to reflect on day-to-day situations relatively closely to their occurrence (cf. Bartlett, Milligan, and Crow, 2015).

\section{Negotiating boundaries}

Fan activities and identities, feminized fan cultures in particular, have a history of being culturally devalued and stigmatized. Consequently, there are fans who take special care to separate their fan identity from other parts of their lives, for example by using different pseudonymous accounts and sometimes by fabricating an online persona (cf. Gerrard, 2017, 2020). In addition, fans can face criticism from within fandom spaces and risk being affected by platform crackdowns, which is especially a concern among marginalized communities who share and create sexually explicit content. In part as a result of this, the use of Discord servers and chat groups has become increasingly common, establishing private and semi-public fan spaces which are carefully organized and managed by their communities. This, however, also means that access often is restricted - the more private and personal these spaces get, with community members opening up about other aspects of their lives, the more apprehensive people are to allow researchers entry. With direct access being limited, creative methods are needed to examine the significance of these hybrid spaces to people's individual fan experience. Moreover, it asks for a strong sensitivity on the researcher's part to ensure that interactions with participants and reports on research findings do not expose techniques or break down boundaries people have deliberately set. It raises the question of how to examine the intersections between different spheres of life and their existence across online and offline spaces, when the people being studied are 
extremely careful in how, where and when these intersections should take place. While not offering any definitive conclusions, this paper aims to further the discussion on these and related challenges.

\section{References}

Bareither, C. (2019). Doing Emotion through Digital Media: An Ethnographic Perspective on Media Practices and Emotional Affordances. Ethnologia Europaea, 49(1), 7-23.

Bartlett, Ruth, Christine Milligan, and Graham Crow. (2015). What Is Diary Method? London: Bloomsbury Publishing UK.

Couldry, N. (2010). Theorising Media as Practice. In B. Bräuchler \& J. Postill (Eds.), Theorising Media and Practice (pp. 35-54). New York: Berghahn Books.

Gerrard, Y. (2017). 'It's a Secret Thing': Digital disembedding through Online Teen Drama Fandom. First Monday, 22(8). https://doi.org/10.5210/fm.v22i8.7877.

Gerrard, Y. (2020). What's in a (Pseudo)Name? Ethical Conundrums for the Principles of Anonymisation in Social Media Research. Qualitative Research. Advance online publication. https://doi.org/10.1177/1468794120922070.

Hills, M. (2017). Foreword. The 'Imaginary Opponents' of Digital Fandom (and Fan Studies). In P. Booth (Ed.), Digital Fandom 2.0: New Media Studies (pp. xi-xx). New York: Peter Lang.

Jørgensen, K. M. (2016). The Media Go-Along: Researching Mobilities with Media at Hand. MedieKultur: Journal of Media and Communication Research, 60, 32-29. https://doi.org/10.7146/mediekultur.v32i60.22429.

Moores, S. (2012). Media, Place and Mobility. Houndmills, Basingstoke, Hampshire: Palgrave Macmillan.

Pink, S., Horst, H.A., Postill, J., Hjorth, L., Lewis, T. \& Tacchi, J. (2016) (Eds.), Digital Ethnography: Principles and Practice. Los Angeles: SAGE.

Richardson, I. \& Hjorth, L. (2017). Mobile Media, Domestic Play and Haptic Ethnography. New Media and Society, 19(10), 1653-67. https://doi.org/10.117/ 1461444817717516. 


\title{
ETHNOGRAPHING BETWEEN SPACES: RESEARCHING TIKTOK FROM AN E ${ }^{3}$ THNOMUSICOLOGICAL PERSPECTIVE
}

\author{
Juan Bermúdez \\ University of Vienna
}

\section{Introduction}

In a deterritorialized and digitally interconnected world a vast number of interrelations between multimedia spaces have been developed and established as an inseparable part of our daily life. This appropriation of the virtual worlds, as well as the development of new digital platforms have not only shaped the interaction between actors, but they have also enabled new forms of musical practices. The investigation of musicking, such as in TikTok offers a large number of theoretical possibilities but at the same time it poses practical and theoretical challenges. In a world where interactions are increasingly happening beyond a physical contact, (ethno)musicologists are forced and encouraged to widen their approaches and methods in order to adjust to these new multimedia realities. In this paper I will outline these challenges and possibilities and I will as well also reflect on the consequences for ethnographic work and methodological approach using TikTok's musicking from an Austrian perspective as an example.

\section{An Ethnomusicological Approach}

In 1964 Alan P. Merriam presented a long-lasting model based on the study of three analytical levels: conceptualization about music, behavior in relation to music and music sound itself. In 1987 this model was expanded by Timothy Rice adding a focus on the individual and his experiences in the process of making music, as well as a diachronic perspective. In 2016, Julio Mendívil contributed to this methodological approach with Christopher Smalls concept of musicking. Mendívil explained: "[...] such an approach allows us to analyze the historical formation of sound's structures, behavior and concepts as a particular process in a given time and place, which involves all the actors musicking (not only playing and hearing, as Rice defines it)" (2016, p. 73). The analysis of multimedia musical practices, such as the practices in TikTok, require, however, more than a successful ethnomusicological model. To overcome the digital challenges, I propose to understand internet and its (musical) practices, as embedded, embodied and everyday, as postulated by Christine Hine (2015). The shift that makes it possible to expand Merriam's model with the required contemporary level, reflects the realities of a multimedia world in thinking in terms of the meaning of internet in the everyday life of the actors, their musical practices, as well as the recognition of internet as an embodied experience that is influenced and determined by forms, discourses, times, objectives, etc., and by the interactions between the human and non-human actors.

\section{Embedded, Embodied, and Everyday - Towards an $E^{3}$ thnographie}

To explore mediatized musical practices, it is firstly indispensable to understand digital and analog media as practices, which are created, discussed, and experienced in everyday situations and contexts synchronously or asynchronously. That is why an 
intensive multi-local and multimedia participatory observation in line with a hermeneutic phenomenological ethnography allows us to concentrate our focus on what people are actively doing with and in a mediatized environment and herewith against a discourse that sees media exclusively as a communication or representation channel used by physical actors. A discourse that creates a strict dichotomous separation between reality and virtuality and which does not perceive digital media as part of knowledge practice, but rather as a passive representational practice. A different approach to the relation between reality and virtuality can be found in the scholastic philosophy: "In scholastic philosophy 'actual' and 'virtual' exist in a dialectical relation rather than in one of radical opposition" (Ryan, 1999, p. 88). This dialectical interdependence between the reality happening at the current moment and the potential reality, meaning the virtual, has an influence on the perception of each of our cultural practices. Therefore their dichotomous separation doesn't show a logical sense.

Secondly, an $e^{3}$ thnographic approach requires a strong focus on individuals and their music-making experiences as individuals or in groups. That is why, it is important to prioritize the use of methods that focus on the learning of multimedia practices related to musicking (see Baily, 2001), but also to the processes that allow the creation and negotiation of the auditory knowledge of the musicking under investigation (see Bermúdez et al., 2018). In addition, the focus shall also lie on the performative creation of musical personae (Auslander, 2006) and on the discussion of cultural behaviors related to them. The same way interactions can take place in spaces beyond the $\mathrm{real} /$ virtual dichotomy, interactions are not tied to a physical body, but much more to the varied characteristics of the actors' identities.

Thirdly, we need a new definition for our ethnographic field and a new approach due to the deterritoralization and multimedia reality of these musical practices. There is no preexisting space within these practices, which we can enter, it is only possible to construct and interact through the continuous multimedia interaction of physical and digital actors or personae. This is why, we need to increasingly focus on 1) interactions continuously created and experienced by the actors of this musicking; 2) the interrelations built, discussed and experienced by the actors of this musicking throughout time; 3) the processes that enable the creation, discussion and experience of personal and public multimedia locations.

\section{Conclusions}

Merriam's Model that can be seen as the fundament of ethnomusicological work, provided the basis for a musicological paradigm in 1964, which encompasses musics in their holistic performativity from a culture-relativistic perspective. The further developments of Merriam's model by Rice (1987) and Mendívil (2016) have enhanced the way that realities of musical worlds of the turn of the century have been included in said model. With approaches like Hine's approach (2015) and a research paradigm that does not see digital media as a passive representation channel or an economical product, but rather as a practice, Merriam's Model gets the support and opportunities needed to overcome challenges posed by contemporary music practices. An $E^{3}$ thnography makes it possible to observe and experience how concepts, behaviors and sounds are historically constructed by the actors of a certain musicking in different 
contexts, how they are socially maintained and how they are individually created and experienced in everyday life in synchronous or asynchronous multimedia situations.

\section{References}

Auslander, P. (2006). Musical Personae. The Drama Review, 50(1), 100-119.

Bermúdez, J., L. Dullnig, S. Gmeiner, H. Matthäus, M. Rogenhofer, F. Schriebl, L. Auer, and B. Brabec de Mori. (2018). Von Klang(-)Wissen und anderen Fischen. Auditive Wissenskulturen von Konzertfach- und Musikologiestudierenden im Vergleich. In B. Brabec de Mori, and M. Winter (Ed.), Auditive Wissenskulturen: Das Wissen klanglicher Praxis (pp. 283-302). Wiesbaden: Springer VS. https://doi.org/10.1007/978-3-658$\underline{\text { 20143-2 } 14}$

Baily, J. (2001). Learning to Perform as a Research Technique in Ethnomusicology. British Journal of Ethnomusicology 10(2), 85-98.

Hine, C. (2015). Ethnography for the Internet: Embedded, Embodied and Everyday. London: Bloomsbury.

Mendívil, J. (2016). The Battle of Evermore. Music as a Never-ending Struggle for the Construction of Meaning. In R. Allgayer-Kaufmann (Ed.), World Music Studies (pp. 6791). Berlin: Logos Verlag.

Merriam, A. P. (1964). The Anthropology of Music. Evanston: Northwestern University Press.

Rice, T. (1987). Toward the Remodeling of Ethnomusicology. Ethnomusicology, 31(3), 469-488.

Ryan, M.-L. (1999). Cyberspace, Virtuality, and the Text. In M.-L. Ryan (Ed.), Cyberspace Textuality: Computer Technology and Literary Theory (pp. 78-107). Bloomington: Indiana University Press.

Small, C. (1998). Musicking: The Meanings of Performing and Listening. Middletown: Wesleyan University Press. 


\title{
METHODOLOGICAL REFLECTIONS ON CAPTURING AUGMENTED SPACE: INSIGHTS FROM AN AUGMENTED REALITY (AR) FIELD STUDY
}

\author{
Moritz Schweiger \\ University of Augsburg \\ Jeffrey Wimmer \\ University of Augsburg
}

Digital-based AR overlays physical (offline) space and adds new layers of meaning to it (Liao \& Humphreys, 2015). This is particularly evident in urban space, which, as a burning glass of media developments, is already affected by a multitude of holographic content (Aurigi \& Cindio, 2008). But how does AR change our perception of urban space and the personal meaning it unfolds in daily life? And how can we capture the reception of meaningful AR content, experienced through head-worn AR, methodically?

To answer these questions, a historical building, which had been destroyed during air raids in the Second World War, was holographically reconstructed on a public city square. In order to resurrect this building in AR, old photographs, paintings and postcards were assessed to program a hologram in its original size and place it at its original location. Using high-tech AR glasses (Microsoft HoloLens 2), test persons were able to move freely around the square, observe the hologram from different angles and walk into it. Thereby, we wanted to illuminate how AR might influence the relation of city dwellers and urban space based on three spatial dimensions: the spatial perception of the square (dimension 1), its spatial meaning in the lives of city dwellers (dimension 2) and their spatial movement patterns on the square (dimension 3).

\section{Methodological challenges when capturing augmented space}

In order to capture the appropriation of augmented space, we relied on a multi-method approach using both qualitative and quantitative tools. Due to its explorative character and constantly changing field conditions, among others the Covid-19 pandemic, we had to critically reflect and adapt our study to several unpredictable obstacles. After evaluating the development of our empirical tools, we can now present insights into the methodical challenges and chances of AR field studies and give an overview of best and worst practices regarding sampling, test persons recruiting, study implementation, and data analysis when capturing the interrelation of physical and augmented space.

Preliminary and follow-up questionnaires and mean value comparisons were used to determine (in)significances in the influence of AR on spatial perception and meaning. The influence on spatial perception was captured via polarity profiles including 20 opposite pairs (e.g. "narrow/spacious", "bare/decorated") deduced from a study by Kuliga et al. (2014, p. 368). Finding standardized items on spatial meaning posed more difficulties, since most studies focus on the significance of specific places (e.g. residence (Manzo, 2005)) instead of analyzing places in general. Thus, we referred to the three-pole-model by Gustafson (2001), who allocates the general meaning of place 
within the comprehensive field of the self, others and the physical environment. This three-pole-model was operationalized into 33 items during an online survey followed by factor analysis and proved appropriate for capturing spatial meaning holistically.

In addition to standardized questionnaires, the influence of AR on spatial perception and meaning was also explored using qualitative thinking-aloud-protocols (TAP). Due to the ongoing methodological discussion on appropriate forms of TAP, especially apparent in $\mathrm{HCl}$ usability research (Alshammari et al., 2015), we decided to pre-test their suitability for our AR field study. For this purpose, the statements, gaze direction and gestures of the subjects were videotaped via the built-in recording system of the Microsoft HoloLens 2 and evaluated. In a first pre-test, we compared the most prevalent forms of TAP:

- Unguided vs. Guided TAP (open vs. space specific questions)

- Concurrent vs. Retrospective TAP (during or after the AR-experience)

It showed that unguided TAP, while undoubtedly evoking unfiltered reactions on usability, is less suited for capturing augmented space. It mainly led to extravagated statements regarding the graphic quality in general or the light weight of the AR glasses. This might be traced back to the fact that head-worn AR is not yet established and many subjects were wearing AR glasses for the first time. In guided TAP, queries can direct the narrative of the subject towards specific aspects of the AR experience, while their disruptive character can be seen as trade-off. With regard to the timing, we found that concurrent TAP is better suited for capturing spontaneous reactions or references to special AR content, while also evoking cognitive overload and a sense of social undesirability regarding passers-by. In retrospective TAP, an ego-centered videorecording of their AR experience was shown to the subjects on a laptop, while their verbal comments were captured via screen recording. This led to more reflected statements and intensive thoughts, since subjects could relive their previous AR experience and focus on specific aspects they had overseen before.

Based on our pre-test, we decided to use guided-concurrent TAP during the AR experience to analyze the influence of the hologram on spatial perception. The effects on spatial meaning were captured right after the AR experience in an interview room close to the city square via guided-retrospective TAP. The spatial movement was collected via locative tracking within the AR glasses. Thereby, we could generate walking lines and compare how subjects allocated themselves towards the hologram, how many walked right into it or didn't dare to break its presence. The combination of both quantitative and qualitative methods proved valuable to capture the reception of space, since some test persons for instance focused entirely on augmented spatial meaning while omitting augmented spatial perception in both the TAPs. Thus, the supplementation with standardized questionnaires helped us to analyze spatial dimensions that had been passed over in the qualitative statements.

Due to the technological and methodological affordances of our field study, an extensive interviewer training was conducted including a detailed interviewer guide and an exploratory video. AR researchers should keep in mind that interviewers need to know how to use high-tech AR glasses, how to accurately place a hologram, how to react to manifold technical issues (e.g. a dislocated or disappearing hologram, abortion of recording) or social interventions (e.g. intrusive by-passers, police controls). 


\section{Methodological challenges for sociological field research during a pandemic}

When doing sociological field research during a pandemic, it is essential be flexible and adapt to daily changing contact restrictions and challenges in recruiting test persons. The creation and adherence to study-specific hygiene and cleaning protocols are crucial for guaranteeing the safety of the test persons and the official approval by local health authorities. Besides, these protocols need to be constantly questioned and adjusted to the actual terms. In our field study, all participants had to constantly wear their masks, the AR glasses, tablets and laptops (used for the follow-up questionnaire and retrospective TAP) were regularly disinfected and interviewers were only allowed to conducted two interviews per day. Test persons who reported contact with a Covid-19 patient within the last two weeks were excluded from the study. By early informing police departments about the officially approved field study, contact controls regarding group sizes at public spaces can be avoided.

\section{References}

Alshammari, T., Alhadreti, O., \& Mayhew, P. (2015). When to ask participants to think aloud: A comparative study of concurrent and retrospective think-aloud methods. International Journal of Human Computer Interaction, 6(3), 48-64.

Aurigi, A. \& Cindio, F. D. (2008). Augmented urban spaces: Articulating the physical and electronic city. London: Routledge.

Gustafson, P. (2001). Meanings of place: Everyday experience and theoretical conceptualizations. Journal of environmental psychology, 21(1), 5-16.

Kuliga, S. F., Thrash, T., Dalton, R. C., \& Hölscher, C. (2015). Virtual reality as an empirical research tool - Exploring user experience in a real building and a corresponding virtual model. Computers, Environment and Urban Systems, 54, 363375.

Liao, T. \& Humphreys, L. (2015). Layar-ed places: Using mobile augmented reality to tactically reengage, reproduce, and reappropriate public space. New Media \& Society, 17(9), 1418-1435.

Manzo, L. C. (2005). For better or worse: Exploring multiple dimensions of place meaning. Journal of Environmental Psychology, 25(1), 67-86. 